\title{
Hydrothermal Synthesis of Nitrogen-Doped Titanium Dioxide and Evaluation of Its Visible Light Photocatalytic Activity
}

\author{
Junjie Qian, Guanjun Cui, Mingjun Jing, Yan Wang, Min Zhang, and Jianjun Yang \\ Key Laboratory for Special Functional Materials, Henan University, Kaifeng 475004, China \\ Correspondence should be addressed to Jianjun Yang, hndxyjj@sina.com
}

Received 14 September 2011; Revised 6 November 2011; Accepted 8 December 2011

Academic Editor: Mietek Jaroniec

Copyright ( $) 2012$ Junjie Qian et al. This is an open access article distributed under the Creative Commons Attribution License, which permits unrestricted use, distribution, and reproduction in any medium, provided the original work is properly cited.

Nitrogen-doped titanium dioxide $\left(\mathrm{N}\right.$-doped $\left.\mathrm{TiO}_{2}\right)$ photocatalyst was synthesized from nanotube titanic acid (denoted as NTA; molecular formula $\mathrm{H}_{2} \mathrm{Ti}_{2} \mathrm{O}_{5} \cdot \mathrm{H}_{2} \mathrm{O}$ ) precursor via a hydrothermal route in ammonia solution. As-synthesized $\mathrm{N}$-doped $\mathrm{TiO}{ }_{2}$ catalysts were characterized by means of X-ray diffraction, transmission electron microscopy, diffuse reflectance spectrometry, Xray photoelectron spectroscopy, electron spin resonance spectrometry and Fourier transform infrared spectrometry. It was found that nanotube ammonium titanate (NAT) was produced as an intermediate during the preparation of N-doped $\mathrm{TiO}_{2}$ from $\mathrm{NTA}_{\text {, as }}$ evidenced by the N1s X-ray photoelectron spectroscopic peak of $\mathrm{NH}_{4}{ }^{+}$at $401.7 \mathrm{eV}$. The catalyst showed much higher activities to the degradation of methylene blue and p-chlorophenol under visible light irradiation than Degussa P25. This could be attributed to the enhanced absorption of $\mathrm{N}$-doped $\mathrm{TiO}_{2}$ in visible light region associated with the formation of single-electron-trapped oxygen vacancies and the inhibition of recombination of photo-generated electron-hole pair by doped nitrogen.

\section{Introduction}

Titania, as a currently known most effective photocatalyst, have been widely applied in purifying air and water, deodorization, and many other environmentally related fields [1]. However, $\mathrm{TiO}_{2}$ can only be induced by ultraviolet (UV), due to its large bandgap of ca. $3 \mathrm{eV}$ [2]. As a result, $\mathrm{TiO}_{2}$ in practical application can only utilize a small fraction $(\sim$ $5 \%$ ) of solar energy [3]. To increase the efficiency for solar energy transformation and utilization, many researchers have attempted to extend the absorption range of $\mathrm{TiO}_{2}$ from UV region to visible light (Vis in short) region by doping various cations [4-6] and anions [7, 8]. It has been found that $\mathrm{N}$ doping induces considerable visible light response of anatase $\mathrm{TiO}_{2}$; the mechanisms for the visible light response of $\mathrm{N}$-doped $\mathrm{TiO}_{2}$, however, still remain disputable. About one decade ago, Asahi et al. reported a visible light active $\mathrm{TiO}_{2-x} \mathrm{~N}_{x}$ film by sputtering a $\mathrm{TiO}_{2}$ target in the mixture of $\mathrm{N}_{2}$ and $\mathrm{Ar}$ (volume ratio 40\%:60\%); and they suggested that the incorporation of dopant $\mathrm{N}$ atom into the crystal lattice of $\mathrm{TiO}_{2}$ via substituting $\mathrm{Ti}$ atom was indispensable for band-gap narrowing and photocatalytic activity generation [9]. In 2003, Irie et al. reported a $\mathrm{TiO}_{2-x} \mathrm{~N}_{x}$ powder prepared by annealing anatase $\mathrm{TiO}_{2}$ under an ammonia flow; and they supposed that the isolated narrow band formed above the valence band of $\mathrm{TiO}_{2}$ was responsible for the visible light response of $\mathrm{N}$-doped $\mathrm{TiO}_{2}$ [10]. Ihara et al. also prepared a visible light responsive photocatalyst by treating the hydrolysis product of $\mathrm{Ti}\left(\mathrm{SO}_{4}\right)_{2}$ in ammonia (a precursor for $\mathrm{N}$ doping); and they deduced that oxygen-deficient sites formed in grain boundaries gave rise to visible light activity of as-prepared $\mathrm{N}$-doped product, while doped $\mathrm{N}$ at oxygendeficient sites played a key role as a blocker for reoxidation [11]. Zhang et al. observed that the visible-light absorption of vacuum-dehydrated product of NTA was proportional to the intensity of electron spin resonance (ESR) signal [12]. We supposed in our previous researches that the visible light sensitization of $\mathrm{N}$-doped $\mathrm{TiO}_{2}$ was due to the formation of single-electron-trapped oxygen vacancies (SETOVs), and doped-N played a role in preventing photogenerated electrons and holes from recombination $[12,13]$.

In the present research, we make use of a hydrothermal method to prepare N-doped $\mathrm{TiO}_{2}$ by selecting NTA as a precursor, hoping to harvest $\mathrm{TiO}_{2}$-based photocatalyst with high visible light activity while heat-treatment temperature is considerably lowered as compared with that for calcination 
of NTA in flowing ammonia [12]. This article reports the preparation and characterization of $\mathrm{N}$-doped $\mathrm{TiO}_{2}$ photocatalyst, as well as its photocatalytic activity for the degradation of methylene blue (MB) and p-chlorophenol (4-CP) under visible light irradiation.

\section{Experimental Section}

2.1. Preparation of Samples. NTA was prepared using the method reported in literature [14]. N-doped $\mathrm{TiO}_{2}$ powders were prepared using a two-step protocol. Firstly, $1 \mathrm{~g}$ of NTA and $50 \mathrm{~mL}$ of ammonia solution (mass fraction $25 \%$ $28 \%$ ) was added into a Teflon-lined stainless steel autoclave $(75 \mathrm{~mL})$ and airproofed and heated at 130,160 and $210^{\circ} \mathrm{C}$ for $3 \mathrm{~h}$ in an oven. Then, the autoclave was cooled in air down to room temperature after the reaction was completed, followed by filtration, drying at $60^{\circ} \mathrm{C}$ in vacuum $(-0.1 \mathrm{MPa})$ overnight, and grounding to yield samples denoted as $\mathrm{N}$ NTA-130, N-NTA-160, and N-NTA-210, respectively. Sample H-NTA-210 for a comparative study was also prepared in the same manners except that distilled water was used to replace ammonia solution.

2.2. Characterization. X-ray diffraction (XRD) patterns were measured with a Philips X'Pert Pro X-ray diffractometer $(\mathrm{Cu}$ $K \alpha$ radiation, $2 \theta$ range $7 \sim 90^{\circ}$, scan step size $0.04^{\circ}$, scanning interval $0.5 \mathrm{~s}$, generator voltage $40 \mathrm{kV}$, tube current $40 \mathrm{~mA})$. A JEM-100CX transmission electron microscope (TEM; JEOL Ltd., Japan) was performed at an accelerating voltage of $100 \mathrm{kV}$ to observe the morphology and microstructure of various as-prepared photocatalysts. Diffuse reflection spectra (DRS) were obtained with a UV-Vis spectrophotometer (UV3010; Shimadzu, Japan; reference: $\left.\mathrm{BaSO}_{4}\right)$. An Axis Ultra X-ray photoelectron spectroscope (XPS; Kratos, England) equipped with a multichannel detector was performed to analyze the chemical states of various photocatalysts, where $\mathrm{Al} K \alpha$ radiation $(h \nu=1486.6 \mathrm{eV})$ was used as the excitation source. All the binding energies were referenced to the $\mathrm{C} 1 \mathrm{~s}$ peak at $284.8 \mathrm{eV}$ of surface adventitious carbon. Electron spin resonance (ESR) spectra were collected with a Brüker ESP 300E apparatus (reference: diphenyl-picryl hydrazide $(\mathrm{DPPH}), g=2.0036)$. Fourier transform infrared (FTIR) spectra were recorded with a Nicolet 360 spectrometer $(\mathrm{Ni}$ colet Company, USA).

2.3. Evaluation of Visible Light Photocatalytic Activity. The photocatalytic activities of various photocatalysts were evaluated by monitoring the degradation of $\mathrm{MB}$ and 4-CP under the irradiation of a $500 \mathrm{~W}$ xenon lamp as the light source $\left(I_{420}=2.1 \mathrm{~mW} / \mathrm{cm}^{2}\right)$ with which a filter and a water cell were attached to eliminate UV $(\lambda<420 \mathrm{~nm})$ and infrared light. Into a quartz reactor $(140 \mathrm{~mL})$ charged with $100 \mathrm{~mL}$ of the aqueous solution of $\mathrm{MB}(10 \mathrm{mg} / \mathrm{L})$ or $4-\mathrm{CP}(0.15 \mathrm{mM})$ was added $100 \mathrm{mg}$ of to-be-tested photocatalyst powder. The adsorption equilibrium of aqueous $\mathrm{MB}$ or $4-\mathrm{CP}$ on the photocatalyt was reached in the reactor prior to irradiation. The concentration of $\mathrm{MB}$ was monitored with a visible light spectrometer (722, Shanghai Jingke Instrument Plant, China) at $664 \mathrm{~nm}$, and that of 4-CP was measured with

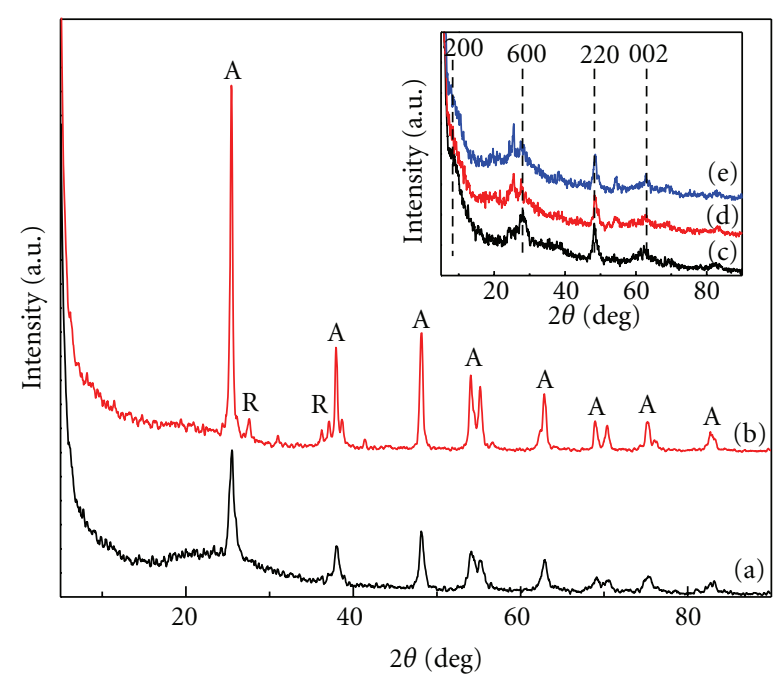

Figure 1: XRD patterns of (a) H-NTA-210 and (b) N-NTA-210. The inset shows the XRD patterns of orthorhombic systems of (c) NTA, (d) N-NTA-130, and (e) N-NTA-160.

an UV-Vis spectrometer (752, Shanghai Oppler Instrument Plant, China) at $225 \mathrm{~nm}$.

\section{Results and Discussion}

The XRD patterns of undoped $\mathrm{TiO}_{2}$ and three $\mathrm{N}$-doped $\mathrm{TiO}_{2}$ samples are compared in Figure 1. Samples N-NTA-130 and N-NTA-160 still retain the orthorhombic form (inset in Figure 1) and nanotubular morphology of precursor NTA (Figure 2). This differs from our previous finding in that the tubular shape of orthorhombic NTA is destroyed in association with conversion into anatase $\mathrm{TiO}_{2}$ when NTA is heated in distilled water at $130^{\circ} \mathrm{C}$ or $160^{\circ} \mathrm{C}$ [15]. However, sample N-NTA-210 shows strong diffraction peaks of anatase $\mathrm{TiO}_{2}$ as well as additional diffraction peaks of rutile phase $\left(27.4,36.1,39.2,41.2,44.1\right.$, and $\left.56.6^{\circ}\right)$, which indicates that hydrothermal treatment of orthorhombic NTA in ammonia solution at an elevated temperature of $210^{\circ} \mathrm{C}$ also facilitates its transformation to $\mathrm{TiO}_{2}$. In the meantime, all the XRD peaks of sample H-NTA-210 can be well indexed as anatase $\mathrm{TiO}_{2}\left(25.4,37.9,48.2,54.1\right.$, and 55.2 ${ }^{\circ}$ ); and both H-NTA210 and N-NTA-210 have diamond shapes, but the size of the former is a little bit smaller than that of the latter (Figure 2). We assume that nanotube ammonium titanate (NAT) is formed as an intermediate through a simple acidbase reaction (1) when NTA is hydrothermally treated in ammonia at $130^{\circ} \mathrm{C}$ or $160^{\circ} \mathrm{C}$, but it is transformed to $\mathrm{TiO}_{2}$ at $210^{\circ} \mathrm{C}$ (reacthion (2)). This supposition is supported by corresponding FTIR data shown in Figure 3. Namely, both N-NTA-130 and N-NTA-160 show a broad band at $3400 \mathrm{~cm}^{-1}$ and a sharp peak at $1630 \mathrm{~cm}^{-1}$ attributed to the stretching vibration and flexural vibration of hydroxyl groups [16] as well as a broad band within $750 \sim 400 \mathrm{~cm}^{-1}$ corresponding to the flexural vibration of $\mathrm{Ti}-\mathrm{O}$ and $\mathrm{Ti}-$ O-Ti groups. Particularly, they also show the stretching and flexural vibration bands of N-H at $3140 \mathrm{~cm}^{-1}$ and 


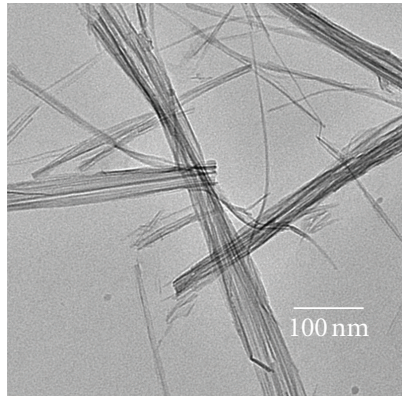

(a)

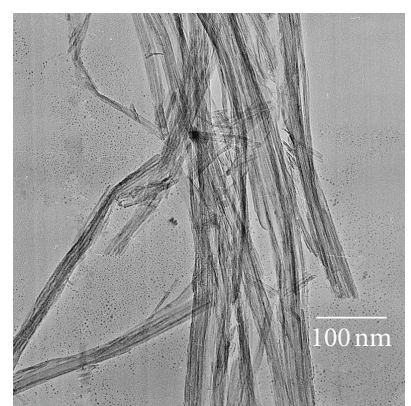

(b)

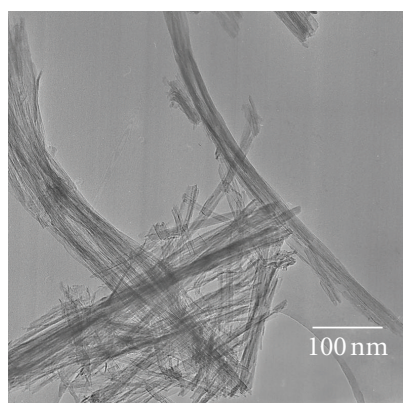

(c)

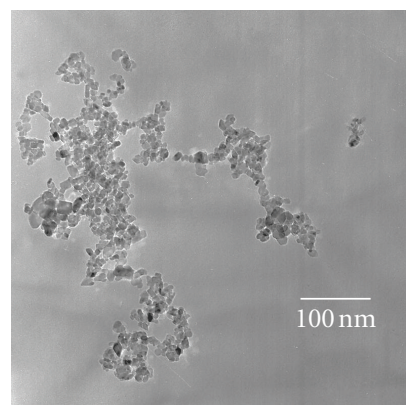

(d)

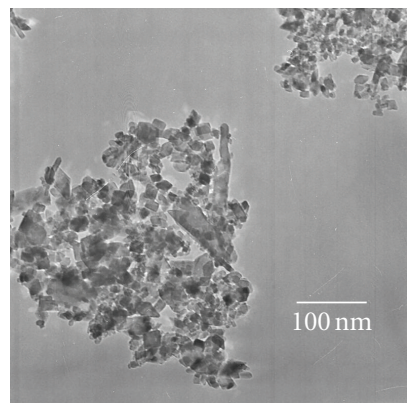

(e)

Figure 2: TEM images of (a) NTA, (b) N-NTA-130, (c) N-NTA-160, (d) H-NTA-210, and (e) N-NTA-210.

$1400 \mathrm{~cm}^{-1}$ [17], which confirms that intermediate NAT is indeed generated during hydrothermal treatment of NTA in ammonia at $130^{\circ} \mathrm{C}$ or $160^{\circ} \mathrm{C}$. However, no stretching and flexural vibration bands of N-H are observed for N-NTA210 , which is due to the decomposition of intermediate NAT at an elevated temperature of $210^{\circ} \mathrm{C}$ :

$$
\begin{aligned}
& \mathrm{H}_{2} \mathrm{Ti}_{2} \mathrm{O}_{5} \cdot \mathrm{H}_{2} \mathrm{O}+x \mathrm{NH}_{3} \cdot \mathrm{H}_{2} \mathrm{O} \\
& \stackrel{130 \sim 160^{\circ} \mathrm{C}}{\longrightarrow}\left(\mathrm{NH}_{4}\right)_{x} \mathrm{H}_{2-x} \mathrm{Ti}_{2} \mathrm{O}_{5} \cdot \mathrm{H}_{2} \mathrm{O}+x \mathrm{H}_{2} \mathrm{O} \\
& \quad(0 \leq x \leq 2), \\
& \left(\mathrm{NH}_{4}\right)_{x} \mathrm{H}_{2-x} \mathrm{Ti}_{2} \mathrm{O}_{5} \cdot \mathrm{H}_{2} \mathrm{O} \\
& \stackrel{210^{\circ} \mathrm{C}}{\longrightarrow} 2 \mathrm{TiO}_{2}+x \mathrm{NH}_{3}+2 \mathrm{H}_{2} \mathrm{O} \\
& (0 \leq x \leq 2) .
\end{aligned}
$$

XPS spectra of NTA and various $\mathrm{N}$-doped $\mathrm{TiO}_{2}$ samples were measured to further elucidate the chemical states of N. As shown in Figure 4, precursor NTA shows no N1s XPS signal; but samples N-NTA-130, N-NTA-160, and NNTA-210 show N1s XPS peaks at $400.0 \mathrm{eV}$ and $401.7 \mathrm{eV}$. It is usually recognized that N1s XPS peak of N-doped $\mathrm{TiO}_{2}$ at $397.0 \mathrm{eV}$ is assigned to atomic Ti-N [12, 18-20]; but the assignment of the N1s XPS peaks at $400.0 \mathrm{eV}$ and $401.7 \mathrm{eV}$ are still under argument. Asahi et al. assigned them as molecularly chemisorbed $\gamma-\mathrm{N}_{2}$, but Sato et al. argued that molecular $\mathrm{N}_{2}$ could not be adsorbed on metal oxide like $\mathrm{TiO}_{2}$ at room temperature and suggested that the N1s core level of $\mathrm{N}$-doped $\mathrm{TiO}_{2}$ at $400.0 \mathrm{eV}$ was attributed to $\mathrm{N}-\mathrm{O}$ bonding (i.e., Ti-O-N), possibly at interstitial site [20]. Irie et al. assigned the N1s XPS peak of $\mathrm{N}$-doped $\mathrm{TiO}_{2}$ at $400.0 \mathrm{eV}$ as NO [10]. In the present research, the N1s XPS peak at ca.

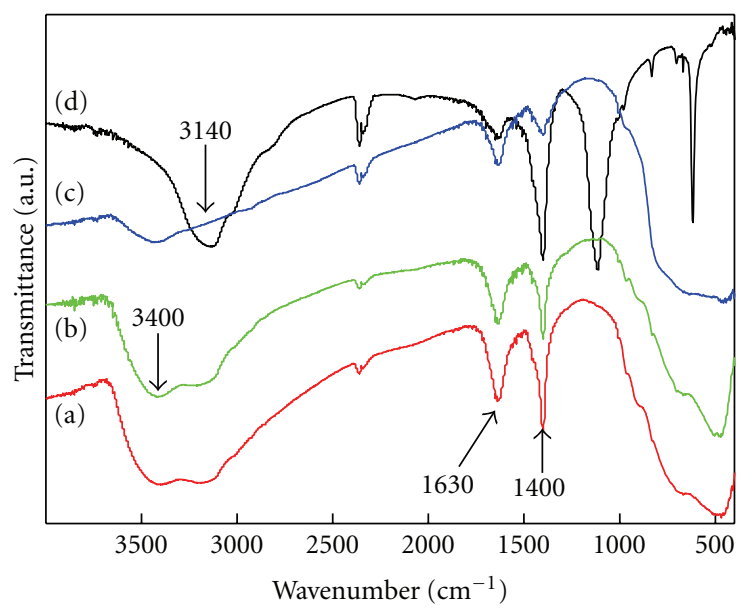

Figure 3: FTIR spectra of (a) N-NTA-130, (b) N-NTA-160, (c) NNTA-210, and (d) reference $\left(\mathrm{NH}_{4}\right)_{2} \mathrm{SO}_{4}$.

$401.7 \mathrm{eV}$ confirms the presence of $\mathrm{N}$ in a third chemical state. Since this N1s XPS peak is only observed for N-NTA-130 and N-NTA-160 but not for N-NTA-210, we tentatively assign it as $\mathrm{NH}_{4}{ }^{+}$of intermediate NAT, as evidenced by relevant FTIR analyses.

Photocatalytic tests indicate that samples NTA, N-NTA130 , and N-NTA-160 have no photocatalytic activity for the discoloration of MB; but sample N-NTA-210 is able to effectively catalyze the discoloration reaction of $\mathrm{MB}$, following the first-order reaction kinetics model (the kinetic constants are ranked as $k(\mathrm{~N}-\mathrm{NTA}-210)>k(\mathrm{H}-\mathrm{NTA}-210)>k(\mathrm{P} 25)$, 


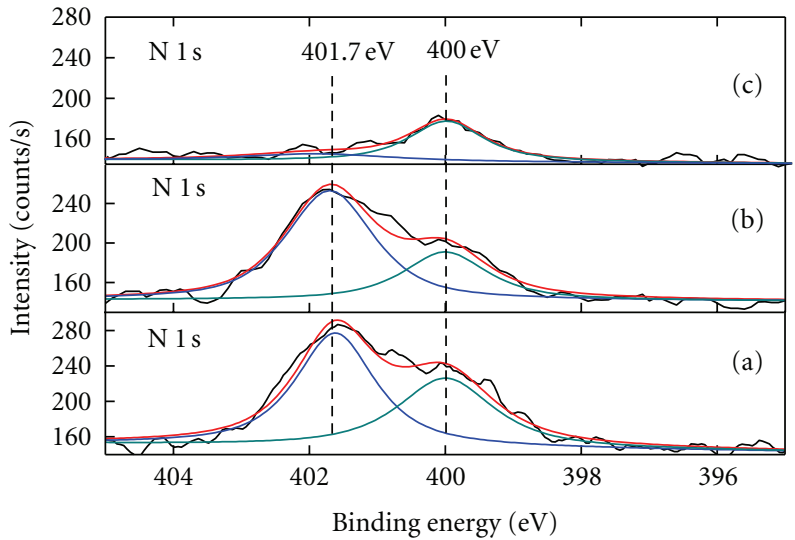

Figure 4: XPS spectra of (a) N-NTA-130, (b) N-NTA-160, and (c) N-NTA-210.

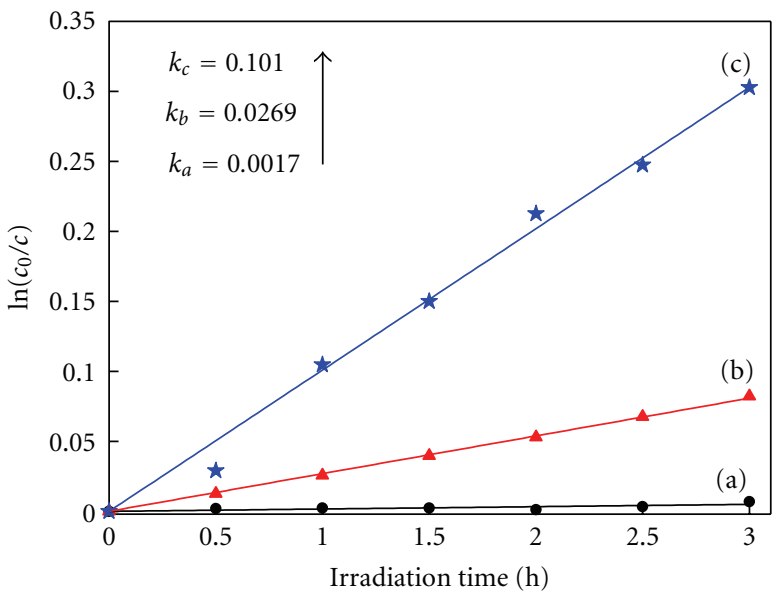

Figure 5: Kinetics of the photocatalytic decomposition of $\mathrm{MB}$ on different $\mathrm{TiO}_{2}$ powders under visible light irradiation: (a) P25, (b) H-NTA-210, and (c) N-NTA-210.

see Figure 5. In the meantime, NTA, N-NTA-130, and NNTA-160 are inert to the degradation of colorless organic pollutant 4-CP under visible light irradiation; but H-NTA210 and N-NTA-210 can well accelerate the degradation of 4-CP under the same conditions, and N-NTA-210 possesses better photocatalytic activity than H-NTA-210 (Figure 6).

It is well known that photocatalytic activity is dependent on light absorption efficiency and separation efficiency of photogenerated electrons and holes. Figure 7 shows the UV-Vis spectra of various photocatalysts. Precursor NTA does not show any absorption in visible light region, but samples H-NTA-210 and N-NTA-210 both show broadened absorptions at $\lambda>400 \mathrm{~nm}$, which corresponds to their enhanced ESR signals at $g=2.003$ (Figure 8) and accounts for better visible photocatalytic activity of N-NTA-210 as compared with Degussa P25. Besides, the present research once again provides evidence to the supposition that SETOV density in $\mathrm{TiO}_{2}$ lattice is proportional to the absorption intensity of the photocatalyst in visible light region (Figure 9) $[12,21-23]$.

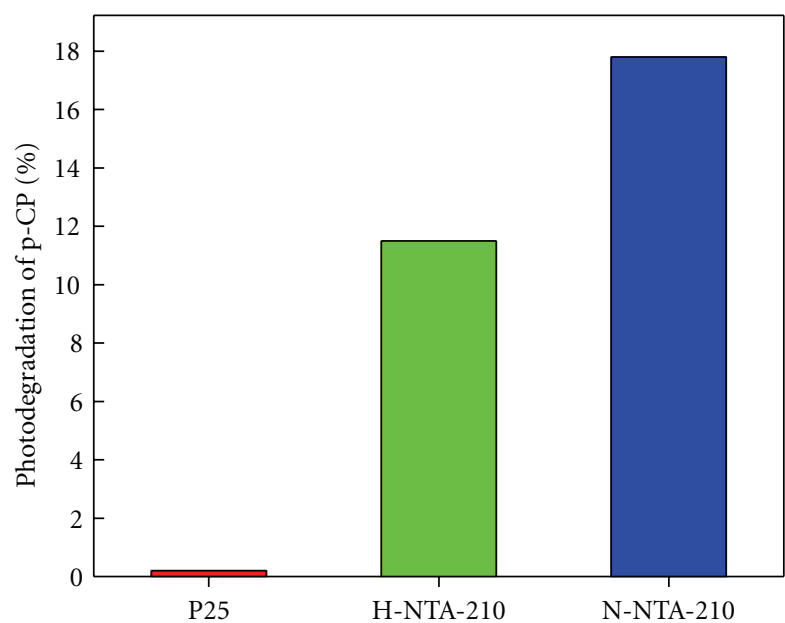

Figure 6: Photocatalytic degradation of p-chlorophenol on P25, HNTA-210, and N-NTA-210.

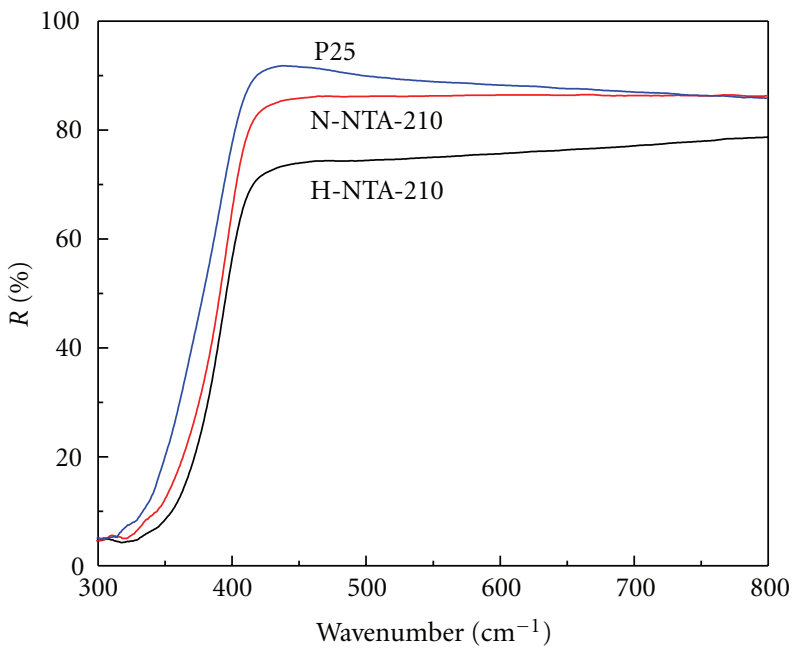

Figure 7: DRS of H-NTA-210, N-NTA-210 and P25.

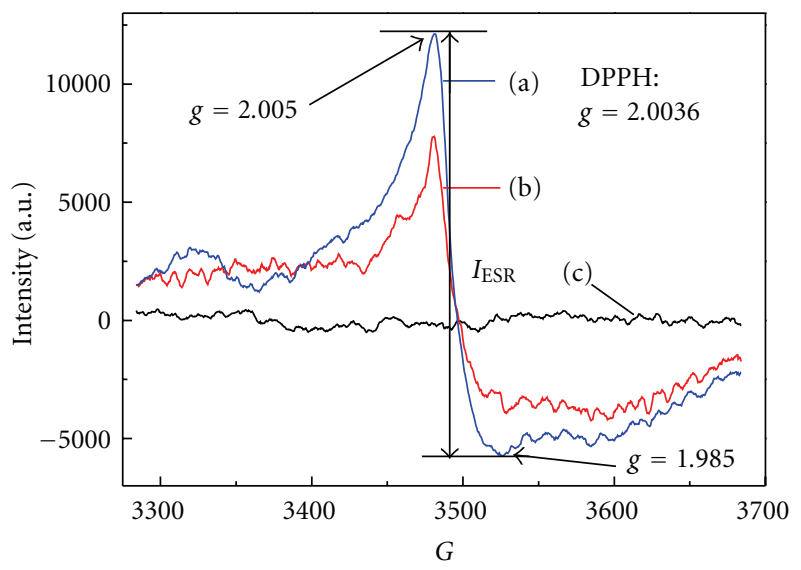

Figure 8: ESR spectra of (a) H-NTA-210, (b) N-NTA-210, and (c) P25 (reference compound: diphenyl picryl hydrazyl (DPPH), $g=$ 2.0036). 


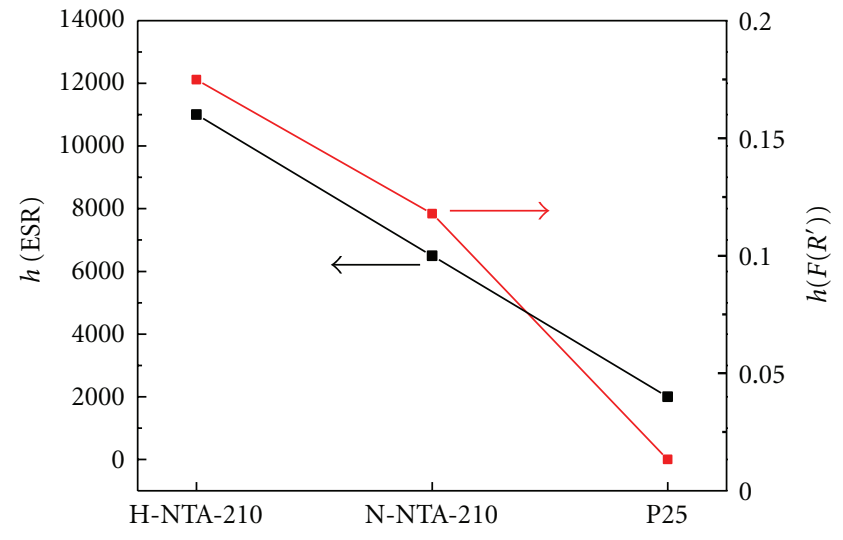

FIgURE 9: The relation between intensity of $g$ value signal and visible light absorption of three $\mathrm{TiO}_{2}$ samples; $h$ (ESR) refers to the signal intensity at $g=2.003, h\left(F\left(R^{\prime}\right)\right)$ refers to the absorption intensity at $450 \mathrm{~nm}, F\left(R^{\prime}\right)=\left(1-R_{\infty}\right)^{2} /\left(2 R_{\infty}\right), F\left(R^{\prime}\right)$ and $R_{\infty}$ refer to absorptivity and reflectance at $\lambda=450 \mathrm{~nm}$.

Aside from the light absorption efficiency, the separation efficiency of electrons and holes is another important factor to influence the activity of photocatalysts. Ordinarily, photoinduced electrons and holes can be generated in photocatalysts under light excitation; and the photoinduced electrons and holes can be separated on the surface of photocatalysts to take part in chemical reactions or recombine. Some researchers have reported that the mixed crystal effect and high crystallinity in a semiconductor is in favor of retarding the recombination of photogenerated electrons and holes $[24,25]$, resulting in enhanced photocatalytic activity. This, however, does not seem to be dominant in the present research. Namely, although H-NTA-210 has a stronger SETOV intensity and broader visible light absorption than N-NTA-210, the former possesses poorer photocatalytic activity than the latter. The enhanced photocatalytic activity of N-NTA-210 as compared with that of H-NTA-210, that we suppose, may be attributed to $\mathrm{N}$ doping which retards the recombination of photoinduced electrons and holes in $\mathrm{TiO}_{2}$ matrix. This can be described using equations (3)-(5) [13]. Briefly, photoinduced electrons in $\mathrm{TiO}_{2}$ matrix arrive at the intraband contributed by SETOV ((3); $V_{0}$ refers to SETOV), but they tend to jump back and recombine with holes. When nitrogen atoms are doped into $\mathrm{TiO}_{2}$ lattices, the back-jumping routes are forbidden and the recombination is reduced greatly, allowing more photoinduced electrons to take part in the chemical reactions. In the meantime, $\mathrm{N}$ atoms in $\mathrm{Ti}-\mathrm{O}-\mathrm{N}$ bond occupy interstitial sites and allow their electron clouds to transfer towards $\mathrm{O}$ atom with a higher electronegativity. As a result, dopant $\mathrm{N}$ in $\mathrm{N}$-doped $\mathrm{TiO}_{2}$ possesses a higher chemical valence than the $\mathrm{N}$ in $\mathrm{NH}_{4}{ }^{+}$and is able to entrap another electron from $V_{\mathrm{o}} \cdot$ ((4); $V_{\mathrm{o}}{ }^{*}$ refers to double-electron-trapped oxygen vacancy). Nevertheless, interstitial $\mathrm{N}$ atom with an excessive electron is unstable and allows its electron could to transfer towards $\mathrm{O}_{2}$ molecule in gas or solution medium (5). Although Ti-O-N bond also exists in samples N-NTA-130 and N-NTA-160 as in
N-NTA-210, N-NTA-130 and N-NTA-160 without SETOV do not possess visible light photocatalytic activity:

$$
\begin{gathered}
V_{\mathrm{o}}{ }^{\cdot}+e^{-} \longrightarrow V_{\mathrm{o}}{ }^{\cdot} \\
V_{\mathrm{o}}{ }^{\cdot}+\mathrm{N} \longrightarrow \mathrm{N}^{\cdot}+V_{\mathrm{o}} \\
\mathrm{N}^{\cdot}+\mathrm{O}_{2} \longrightarrow \mathrm{O}_{2}{ }^{-}+\mathrm{N}
\end{gathered}
$$

\section{Summary}

A simple and mild hydrothermal method has been established to prepare nanoscale $\mathrm{N}$-doped $\mathrm{TiO}_{2}$ photocatalyst with good visible light catalytic activity, where heat treatment of precursor NTA in ammonia solution at $210^{\circ} \mathrm{C}$ for $3 \mathrm{~h}$ facilitates structural transformation from orthorhombic NTA to $\mathrm{N}$-doped $\mathrm{TiO}_{2}$. Heat treatment of the same precursor at lowered temperature of $130^{\circ} \mathrm{C}$ and $160^{\circ} \mathrm{C}$ gives rise to intermediate NAT deserving further research, a potential precursor for fabricating novel $\mathrm{N}$-doped $\mathrm{TiO}_{2}$. As-prepared N-NTA-210 possesses better photocatalytic performance than Degussa P25 for the degradation of MB and 4-CP under visible light irradiation, which is attributed to the formation of a large number of SETOV on the surface of $\mathrm{N}$-doped $\mathrm{TiO}_{2}$ and the occupation of interstitial sites in the crystal lattice of $\mathrm{TiO}_{2}$ by dopant $\mathrm{N}$ as $\mathrm{Ti}-\mathrm{O}-\mathrm{N}$.

\section{Acknowledgments}

The authors thank the National Natural Science Foundation of China (no. 20973054) for financial support.

\section{References}

[1] M. R. Hoffmann, S. T. Martin, W. Choi, and D. W. Bahnemann, "Environmental applications of semiconductor photocatalysis," Chemical Reviews, vol. 95, no. 1, pp. 69-96, 1995.

[2] S. P. Kowalczyk, F. R. McFeely, L. Ley, V. T. Gritsyna, and D. A. Shirley, "The electronic structure of $\mathrm{SrTiO}_{3}$ and some simple related oxides $\left(\mathrm{MgO}, \mathrm{Al}_{2} \mathrm{O}_{3}, \mathrm{SrO}, \mathrm{TiO}_{2}\right)$," Solid State Communications, vol. 23, no. 3, pp. 161-169, 1977.

[3] U. Siemon, D. Bahnemann, J. J. Testa, D. Rodríguez, M. I. Litter, and N. Bruno, "Heterogeneous photocatalytic reactions comparing $\mathrm{TiO}_{2}$ and $\mathrm{Pt} / \mathrm{TiO}_{2}$," Journal of Photochemistry and Photobiology A, vol. 148, no. 1-3, pp. 247-255, 2002.

[4] M. Mrowetz, W. Balcerski, A. J. Colussi, and M. R. Hoffmann, "Oxidative power of nitrogen-doped $\mathrm{TiO}_{2}$ photocatalysts under visible illumination," Journal of Physical Chemistry B, vol. 108, no. 45, pp. 17269-17273, 2004.

[5] W. Choi, A. Termin, and M. R. Hoffmann, "The role of metal ion dopants in quantum-sized $\mathrm{TiO}_{2}$ : correlation between photoreactivity and charge carrier recombination dynamics," Journal of Physical Chemistry, vol. 98, no. 51, pp. 13669-13679, 1994.

[6] M. Takeuchi, H. Yamashita, M. Matsuoka et al., "Photocatalytic decomposition of $\mathrm{NO}$ under visible light irradiation on the Cr-ion-implanted $\mathrm{TiO}_{2}$ thin film photocatalyst," Catalysis Letters, vol. 67, no. 2-4, pp. 135-137, 2000.

[7] J. L. Gole, J. D. Stout, C. Burda, Y. Lou, and X. Chen, "Highly efficient formation of visible light tunable $\mathrm{TiO}_{2-x} \mathrm{~N}_{x}$ photocatalysts and their transformation at the nanoscale," 
Journal of Physical Chemistry B, vol. 108, no. 4, pp. 1230-1240, 2004.

[8] H. Irie, Y. Watanabe, and K. Hashimoto, "Carbon-doped anatase $\mathrm{TiO}_{2}$ powders as a visible-light sensitive photocatalyst," Chemistry Letters, vol. 32, no. 8, pp. 772-773, 2003.

[9] R. Asahi, T. Morikawa, T. Ohwaki, K. Aoki, and Y. Taga, "Visible-light photocatalysis in nitrogen-doped titanium oxides," Science, vol. 293, no. 5528, pp. 269-271, 2001.

[10] H. Irie, Y. Watanabe, and K. Hashimoto, "Nitrogen-concentration dependence on photocatalytic activity of $\mathrm{TiO}_{2-x} \mathrm{~N}_{x}$ powders," Journal of Physical Chemistry B, vol. 107, no. 23, pp. 5483-5486, 2003.

[11] T. Ihara, M. Miyoshi, Y. Iriyama, O. Matsumoto, and S. Sugihara, "Visible-light-active titanium oxide photocatalyst realized by an oxygen-deficient structure and by nitrogen doping," Applied Catalysis B, vol. 42, no. 4, pp. 403-409, 2003.

[12] S. Zhang, W. Li, Z. Jin et al., "Study on ESR and interrelated properties of vacuum-dehydrated nanotubed titanic acid," Journal of Solid State Chemistry, vol. 177, no. 4-5, pp. 1365-1371, 2004.

[13] Y. Wang, C. Feng, M. Zhang, J. Yang, and Z. Zhang, "Visible light active $\mathrm{N}$-doped $\mathrm{TiO}_{2}$ prepared from different precursors: origin of the visible light absorption and photoactivity," Applied Catalysis B, vol. 104, no. 3-4, pp. 268-274, 2011.

[14] J. Yang, Z. Jin, X. Wang et al., "Study on composition, structure and formation process of nanotube $\mathrm{Na}_{2} \mathrm{Ti}_{2} \mathrm{O}_{4}(\mathrm{OH})_{2}$," Journal of the Chemical Society. Dalton Transactions, no. 20, pp. 38983901, 2003.

[15] G. Cui, Z. Xu, Y. Wang, M. Zhang, and J. Yang, "A new method to prepare the novel anatase $\mathrm{TiO}_{2}$," Surface Review and Letters, vol. 15, no. 4, pp. 509-513, 2008.

[16] P. M. Kumar, S. Badrinarayanan, and M. Sastry, "Nanocrystalline $\mathrm{TiO}_{2}$ studied by optical, FTIR and X-ray photoelectron spectroscopy: correlation to presence of surface states," Thin Solid Films, vol. 358, no. 1, pp. 122-130, 2000.

[17] B. Erdem, R. A. Hunsicker, G. W. Simmons, E. David Sudol, V. L. Dimonie, and M. S. El-Aasser, "XPS and FTIR surface characterization of $\mathrm{TiO}_{2}$ particles used in polymer encapsulation," Langmuir, vol. 17, no. 9, pp. 2664-2669, 2001.

[18] N. C. Saha and H. G. Tompkins, "Titanium nitride oxidation chemistry: an x-ray photoelectron spectroscopy study," Journal of Applied Physics, vol. 72, no. 7, pp. 3072-3079, 1992.

[19] S. K. Joung, T. Amemiya, M. Murabayashi, and K. Itoh, "Mechanistic studies of the photocatalytic oxidation of trichloroethylene with visible-light-driven $\mathrm{N}$-doped $\mathrm{TiO}_{2}$ photocatalysts," Chemistry, vol. 12, no. 21, pp. 5526-5534, 2006.

[20] S. Sato, R. Nakamura, and S. Abe, "Visible-light sensitization of $\mathrm{TiO}_{2}$ photocatalysts by wet-method $\mathrm{N}$ doping," Applied Catalysis A, vol. 284, no. 1-2, pp. 131-137, 2005.

[21] C. Burda, Y. Lou, X. Chen, A. C. S. Samia, J. Stout, and J. L. Gole, "Enhanced nitrogen doping in $\mathrm{TiO}_{2}$ nanoparticles," Nano Letters, vol. 3, no. 8, pp. 1049-1051, 2003.

[22] K. Yamada, H. Yamane, S. Matsushima et al., "Effect of thermal treatment on photocatalytic activity of $\mathrm{N}$-doped $\mathrm{TiO}_{2}$ particles under visible light," Thin Solid Films, vol. 516, no. 21, pp. 7482-7487, 2008.

[23] Z. Lin, A. Orlov, R. M. Lambert, and M. C. Payne, "New insights into the origin of visible light photocatalytic activity of nitrogen-doped and oxygen-deficient anatase $\mathrm{TiO}_{2}$," Journal of Physical Chemistry B, vol. 109, no. 44, pp. 20948-20952, 2005.

[24] S. Liu, J. Yu, and S. Mann, "Synergetic codoping in fluorinated $\mathrm{Ti}_{1-x} \mathrm{Zr}_{x} \mathrm{O}_{2}$ hollow microspheres," Journal of Physical Chemistry C, vol. 113, no. 24, pp. 10712-10717, 2009.
[25] I. Shiyanovskaya and M. Hepel, "Decrease of recombination losses in bicomponent $\mathrm{WO}_{3} / \mathrm{TiO}_{2}$ films photosensitized with cresyl violet and thionine," Journal of the Electrochemical Society, vol. 145, no. 11, pp. 3981-3985, 1998. 


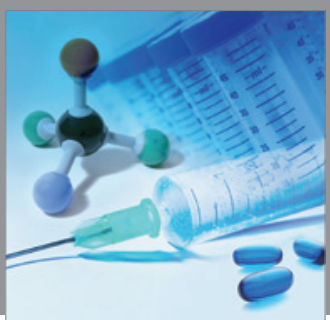

International Journal of

Medicinal Chemistry

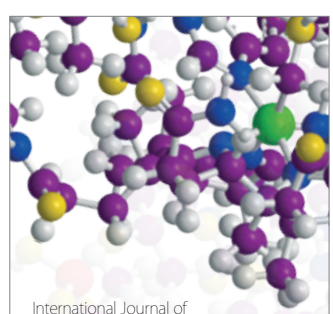

Carbohydrate Chemistry

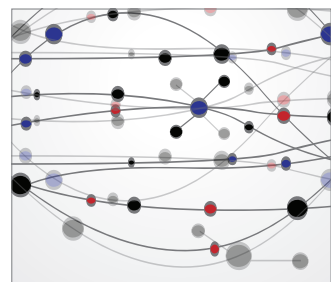

The Scientific World Journal
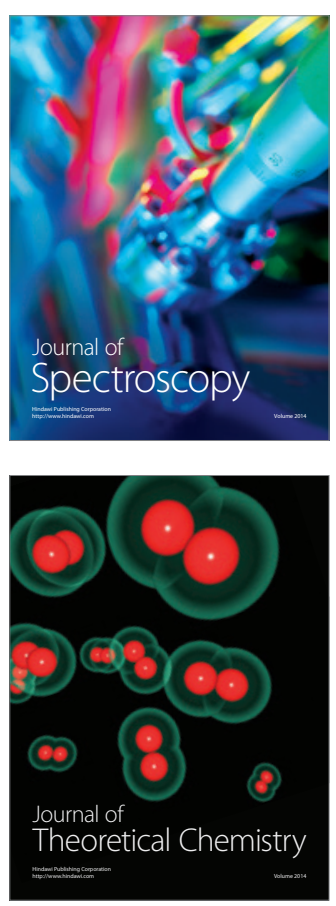
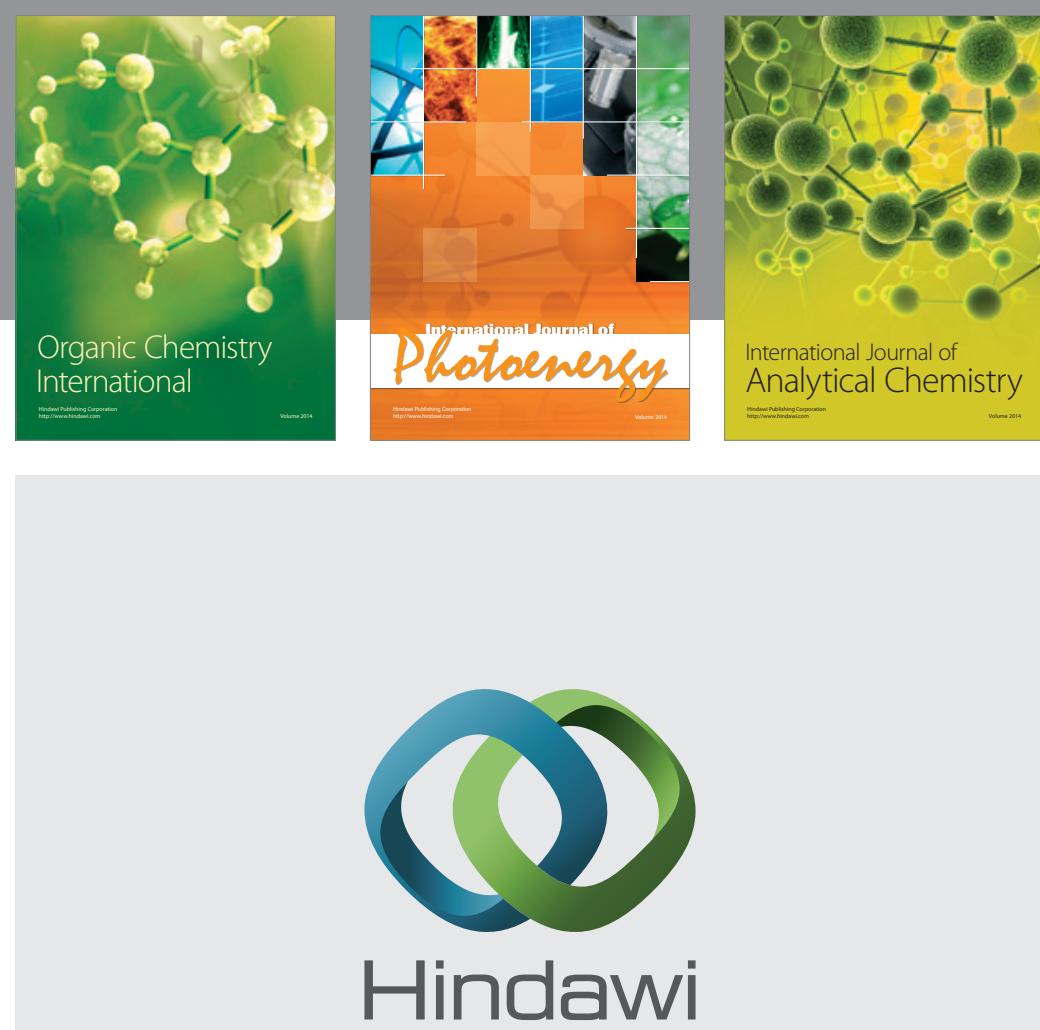

Submit your manuscripts at

http://www.hindawi.com
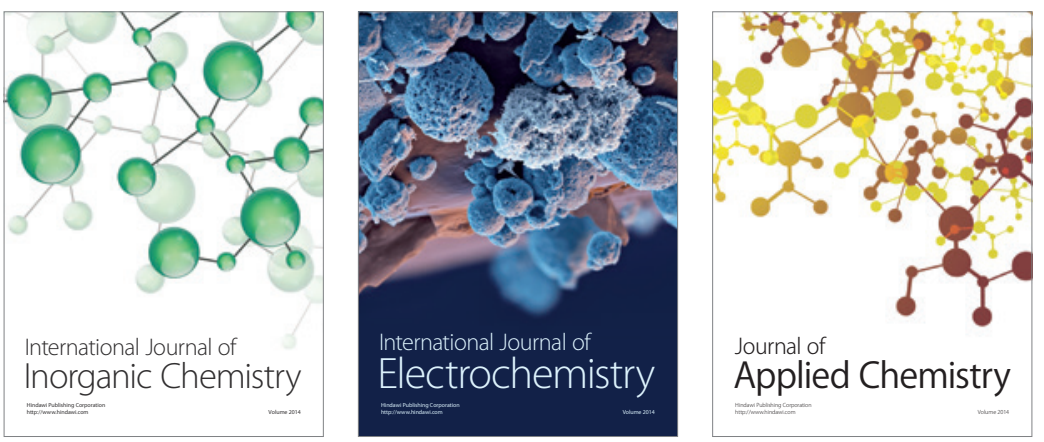

Journal of

Applied Chemistry
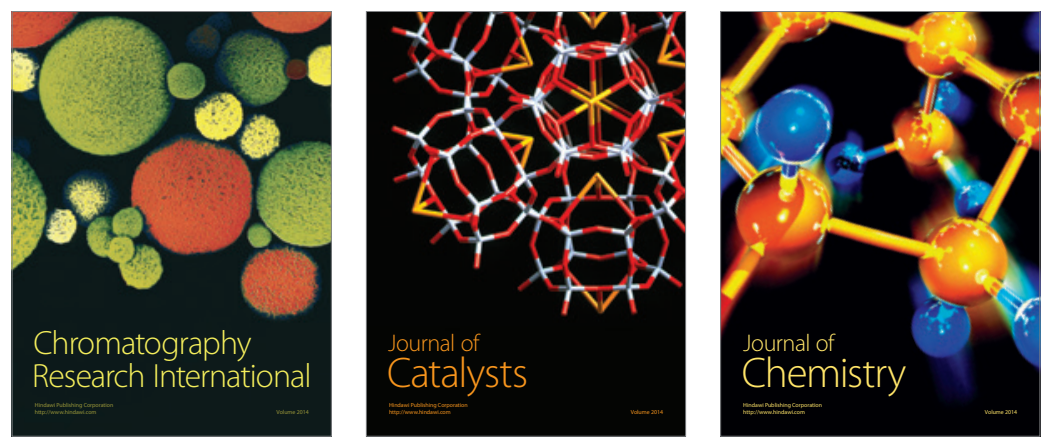
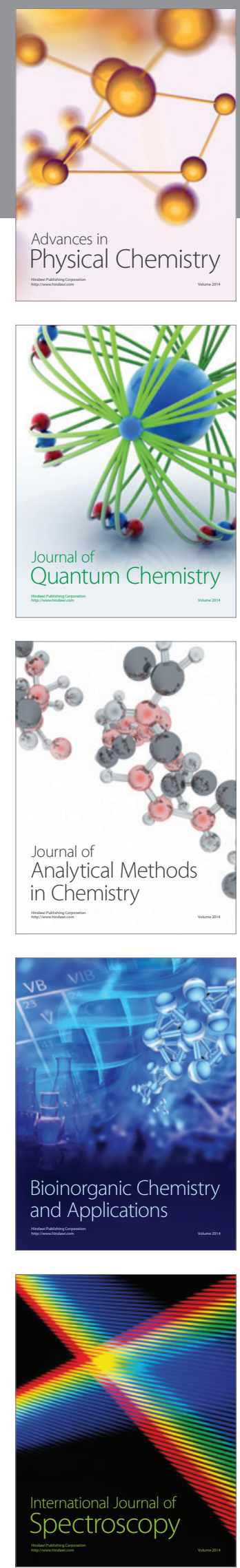